\title{
MHD Boundary Layer Behaviour over a Moving Surface in a Nanofluid under the Influence of Convective Boundary Conditions
}

\author{
Mohamed Abdel-wahed 1,* - Tarek Emam 2,3 \\ ${ }^{1}$ Benha University, Faculty of Engineering at Benha, Egypt \\ 2 Ain Shams University, Faculty of Science, Egypt \\ 3 University of Jeddah, Faculty of Science and Arts, Saudi Arabia
}

The present work provides an analysis of the hydro-magnetic nanofluid boundary layer over a moving surface with variable thickness in the presence of nonlinear thermal radiation and convective boundary conditions. The governing partial differential equations system that describes the problem is converted to a system of ordinary differential equations by the similarity transformation method; such a system is solved numerically. The velocity, temperature, and nanoparticle concentration of the boundary layer are plotted and investigated in details. Moreover, the surface skin friction, rate of heat and mass transfer are deduced and explained in detail.

Keywords: Nanofluids, MHD flow, convective conditions, non-linear thermal radiation

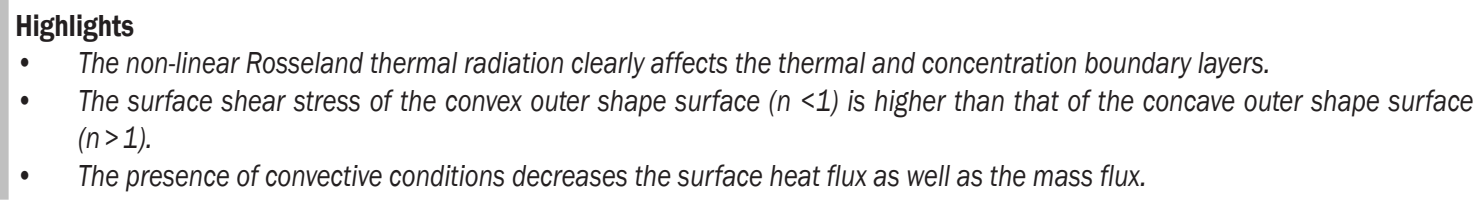

\section{INTRODUCTION}

Choi [1] has suggested the injection of nano-size particles into regular fluids, such as water and oil. $\mathrm{He}$ has proved experimentally that the injection of these particles improves the thermal conductivity of the fluid. This conclusion has opened the way to use these new fluids in chemical engineering, mechanical engineering, medicine, and many other fields.

Industrial applications of nanofluids, such as cooling processes, paper production, glass blowing, plastic extrusion, and wire drawing. are modeled by the mathematical model of boundary layer flow. In such a model, two important concepts are considered by researchers. The first concept is that the fluid and nanoparticles are assumed to be in thermal equilibrium, and no slip may occur between the fluid molecules and nanoparticles. Thus, the concentration of nanoparticles within the boundary layer is considered to be uniform. Taking this concept into consideration, Hamad [2] has found an analytical solution of natural convection flow of a nanofluid over a linearly streaching sheet in the presence of a magnetic field. Yacob et al. [3] numerically studied the problem of steady boundary layer shear flow over a stretching/shrinking surface with a convective boundary condition. Alsaedi et al. [4] have studied the effect of heat generation or absorption on stagnation point flow of a nanofluid over a surface with convective boundary conditions. Elbashbeshy et al. [5] deduced an exact solution for the nanofluid boundary layer over a moving surface subjected to the magnetic field in the presence of suction or injection. Abu Bakar et al. [6] have studied the slip effect and the convective boundary conditions on the boundary layer flow over a stretching sheet. Öztürk et al. [7] have investigated the effects of slip flow of nanofluid and constant heat flux on parallel heated plates.

The second concept is that there are several slip mechanisms that may occur due to Brownian motion and the thermophoresis phenomena so that the distribution of the nanoparticles within the regular fluid is considered to be non-uniform. This assumption has been investigated by Noghrehabadi et al. [8] as they studied the effect of the slip boundary conditions on the heat transfer characteristics of stretching sheet considering the effect of nanoparticles Brownian motion and the thermophoresis forces. Rahman et al. [9] investigated the dynamics of the natural convection boundary layer flow of a viscous incompressible Nanofluid over a nonlinear stretching sheet in the presence of a magnetic field with thermal radiation. Ramesh et al. [10] have investigated the influence of heat source or on a non-Newtonian fluid with nanoparticles over a stretching sheet. The effect of thermal radiation for a magnetohydrodynamic (MHD) boundary layer over a stretching sheet with convective boundary conditions was studied by Nadeem et al. 
[11]. Chamkha et al. [12] investigated the influence of viscous dissipation and magnetic field on natural convection from a vertical plate in a non-Darcy porous medium saturated with a nanofluid. RamReddy et al. [13] examined the effect of Soret parameter on mixed convective flow along a vertical plate in a Nanofluid under a convective boundary condition. Ibrahim et al. [14] have considered the slip boundary conditions in velocity, temperature and concentration to study the boundary layer flow and heat transfer of a nanofluid. Hayat et al. [15] analysed the MHD boundary layer flow of nanofluid over a permeable stretching sheet with convective type boundary conditions for heat and mass transfer process.

All of the above studies have considered flat surfaces, whether vertical or horizontal, so the surface thickness is constant and not variable. Even though industrial applications may include cases of variable thickness surfaces, Fang et al. [16] studied the behaviour of the momentum boundary layer over a moving surface with variable thickness. Elbashbeshy et al. [17] extended the work of Fang to study the momentum and thermal boundary layer over a flatness plate in the presence of thermal radiation. In this work, the authors have assumed that no slip occurs between the fluid molecules and the nanoparticles, which is consistent with the first concept. Abdel-wahed et al. [18] extended the works of Fang and Elbashbeshy to investigate the boundary layer over a moving flatness plate in a nanofluid considering the effects of Brownian motion and the thermophoresis force with heat generation.

The objective of this work is to study the MHD boundary layer with convective boundary conditions over a flatness-moving surface taking the nanoparticles' Brownian motion and thermophoresis force into account. In addition, it is assumed that the boundary layer is subjected to non-linear Rosseland thermal radiation as modelled by Astreios et al. [19] and Abdel-wahed et al. [20].

\section{METHODS}

As shown in Fig. 1, we consider a surface with a flatness profile specified by $y=\delta(x+b)^{\frac{1-n}{2}}$ moving with nonlinear velocity $U w(x)=a(x+b)^{n}$ along the $x$-axis. It is also assumed that the bottom surface of the plate is heated by a hot convection fluid of temperature $T_{w}$ that provides a heat transfer coefficient $h$. Moreover, a magnetic field of strength $B(x)=B_{0}(x+b)^{\frac{n-1}{2}}$ and a thermal radiation of heat flux $q_{r}=-\left(\frac{4 \sigma^{*}}{3 \alpha^{*}}\right) \frac{\partial T^{4}}{\partial y}$ are applied normally to the surface and parallel to the $y$ axis. The upper surface of the plate is subjected to a steady- laminarincompressible viscous manofluid with temperature $T$ and nanoparticle concentration $C$. The end of the boundary layer has an ambient temperature $T_{\infty}$ and concentration $C_{\infty}$.

It is noteworthy that $n$ is the shape parameter. It is assumed that $n>-1$ in this work for the validity of the similarity variable and functions.

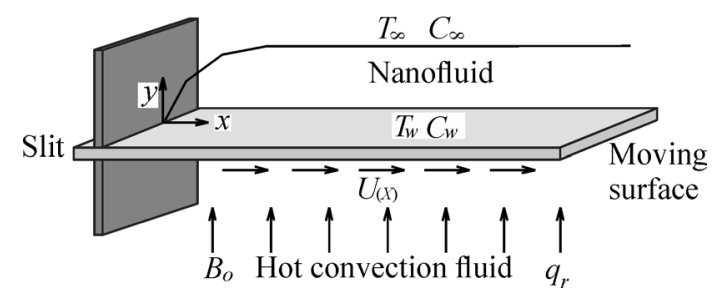

Fig. 1. Physical model and coordinate system

The governing boundary layer equations for such model with nonlinear Rosseland thermal radiation with convective boundary conditions [15] and [18] can be written as:

$$
\begin{aligned}
& \frac{\partial u}{\partial x}+\frac{\partial v}{\partial y}=0, \\
& u \frac{\partial u}{\partial x}+v \frac{\partial u}{\partial y}=v \frac{\partial^{2} u}{\partial y^{2}}-\frac{\sigma B^{2}(x)}{\rho} u, \\
& \left\{\begin{array}{c}
u \frac{\partial T}{\partial x}+v \frac{\partial T}{\partial y}= \pm \frac{\partial^{2} T}{\partial y^{2}} \\
+\left(\frac{1}{\rho C p}\right) \frac{\partial q_{r}}{\partial y} \\
+\tau\left[D_{B} \frac{\partial C}{\partial y} \frac{\partial T}{\partial y}+\frac{D_{T}}{T_{\infty}}\left(\frac{\partial T}{\partial y}\right)^{2}\right]
\end{array}\right\}, \\
& u \frac{\partial C}{\partial x}+v \frac{\partial C}{\partial y}=D_{B} \frac{\partial^{2} C}{\partial y^{2}}+\frac{D_{T}}{T_{\infty}}\left(\frac{\partial^{2} T}{\partial y^{2}}\right),
\end{aligned}
$$

with boundary conditions:

$$
\left\{\begin{array}{c}
\text { at } y=\delta(x+b)^{\frac{1-n}{2}} \\
u=U_{w}, v=0, q_{r}-k \frac{\partial T}{\partial y}=h\left(T_{w}-T\right), \\
-D_{m} \frac{\partial C}{\partial y}=k_{m}\left(C_{w}-C\right) \\
\text { as } y \rightarrow \infty \\
u=0, v=0, T=T_{\infty}, C=C_{\infty}
\end{array}\right\} \text {. }
$$




\section{SIMILARITY TRANSFORMATION \& SOLUTION}

We look for a similarity solution of Eqs. (1) to (4) with the boundary conditions, Eq. (5) using the following non-dimensional functions:

$$
\left\{\begin{array}{c}
\eta=y \sqrt{\left(\frac{n+1}{2}\right)\left(\frac{a(x+b)^{n-1}}{v}\right)} \\
\psi=\sqrt{\left(\frac{2}{n+1}\right)(x+b)^{n+1} a v F(\eta)} \\
T=\theta(\eta)[T w-T \infty]+T \infty \\
C=\varphi(\eta)[C w-C \infty]+C \infty
\end{array}\right\},
$$

where $\eta$ is the similarity variable, and $\psi$ is the stream function which is defined as $u=\partial \psi / \partial y$ and $v=\partial \psi / \partial x$ which satisfies Eq. (1) and $\theta(\eta), \phi(\eta)$ represent the dimensionless temperature and concentration, respectively.

Substituting Eq. (6) into Eqs. (2) to (4), one can obtain the following ordinary differential equations:

$$
\begin{aligned}
& F^{\prime \prime \prime}+F F^{\prime \prime}-\left(\frac{2 n}{n+1}\right) F^{\prime 2}-\left(\frac{2}{n+1}\right) M F^{\prime}=0, \\
& \left\{\begin{array}{c}
3 \theta^{\prime \prime}+R_{d} \frac{\left[\left(1+\left(\theta_{w}-1\right) \theta\right)^{4}\right]}{\left(\theta_{w}-1\right)} \\
+3 \operatorname{Pr}\left[F \theta^{\prime}+N b \theta^{\prime} \varphi^{\prime}+N t \theta^{\prime 2}\right]=0
\end{array}\right\}, \\
& \varphi^{\prime \prime}+\frac{1}{2} L e F \varphi^{\prime}+\left(\frac{N t}{N b}\right) \theta^{\prime \prime}=0,
\end{aligned}
$$

with boundary conditions:

$$
\left\{\begin{array}{c}
F(\alpha)=\alpha\left(\frac{1-n}{1+n}\right), F^{\prime}(\alpha)=1 \\
\theta^{\prime}(0)=-\left(\frac{3 \gamma_{1} \gamma_{2}}{4 \gamma_{2} R_{d} \theta_{w}^{3}+3 \gamma_{1} \sqrt{\frac{1+n}{2}}}\right)[1-\theta(0)], \\
\varphi^{\prime}(0)=-\gamma_{3}[1-\varphi(0)], \\
F^{\prime}(\infty)=0, \quad \theta(\infty)=0, \quad \varphi(\infty)=0
\end{array}\right\}
$$

Here primes denote differentiation with respect to $\eta$. The parameter $\alpha=\delta \sqrt{\frac{1+n}{2} \frac{a}{v}}$ is the surface thickness parameter. So $\eta=\alpha=\delta \sqrt{\frac{1+n}{2} \frac{a}{v}}$ indicates the plate surface. Upon defining $F(\eta)=f(\eta-\alpha)=f(\zeta)$, the similarity Eqs. (7) to (9) and the associated boundary conditions Eq. (10) become:

$$
f^{\prime \prime \prime}+f f^{\prime \prime}-\left(\frac{2 n}{n+1}\right) f^{\prime 2}-\left(\frac{2}{n+1}\right) M f^{\prime}=0
$$

$$
\left\{\begin{array}{c}
{\left[1+\frac{4 R d}{3}\left(1+\left(\theta_{w}-1\right) \theta\right)^{3}\right] \theta^{\prime \prime}} \\
+4 R d\left(\theta_{w}-1\right)\left[1+\left(\theta_{w}-1\right) \theta\right]^{2} \theta^{\prime 2} \\
+\operatorname{Pr}\left[f \theta^{\prime}+N b \theta^{\prime} \varphi^{\prime}+N t \theta^{\prime 2}\right]=0 \\
\varphi^{\prime \prime}+\frac{1}{2} L e f \varphi^{\prime}+\left(\frac{N t}{N b}\right) \theta^{\prime \prime}=0,
\end{array}\right.
$$

with boundary conditions:

$$
\left\{\begin{array}{c}
f(0)=\alpha\left(\frac{1-n}{1+n}\right) \sqrt{\frac{1+n}{2}}, f^{\prime}(0)=1, \\
\theta^{\prime}(0)=-\left(\frac{3 \gamma_{1} \gamma_{2}}{4 \gamma_{2} R d \theta_{w}^{3}+3 \gamma_{1} \sqrt{\frac{1+n}{2}}}\right)[1-\theta(0)], \\
\varphi^{\prime}(0)=-\gamma_{3}[1-\varphi(0)] \\
f^{\prime}(\infty)=0, \theta(\infty)=0, \quad \varphi(\infty)=0
\end{array}\right\}
$$

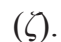

Here primes denote differentiation with respect to

It is worth mentioning that the value of the shape parameter $n$ controls the boundary layer behaviour such that for $n=1$ the boundary condition Eq. (14) reduced to $f(0)=0$ which refers to an impermeable surface, while for $n<1$ the indicated boundary condition becomes $f(0)>0$ which refers to suction. Moreover, $n>-1$ corresponds to $f(0)<0$ which refers to injection.

The systems of Eqs. (11) to (13) together with the boundary conditions Eq. (14) are solved using a shooting method. In this process, it is necessary to choose a suitable finite value $\zeta \rightarrow \infty$, say $\zeta_{\infty}$. To solve the problem, it is required to have the values of $f^{\prime \prime}(0)$, $\theta^{\prime}(0)$ and $\phi^{\prime}(0)$, which are not given in the problem. Suitable guessing values for $f^{\prime \prime}(0), \theta^{\prime}(0)$ and $\phi^{\prime}(0)$ are chosen and then integration is carried out. Comparing the calculated values of $f^{\prime}, \theta$ and $\phi$ at $\zeta=\zeta_{\max } \approx 10$ with the given boundary conditions $f^{\prime}\left(\zeta_{\infty}\right)=0, \theta\left(\zeta_{\infty}\right)=0$ and $\phi\left(\zeta_{\infty}\right)=0$, the estimated values, $f^{\prime \prime}(0), \theta^{\prime}(0)$ and $\phi^{\prime}(0)$ are adjusted. Then taking a series of values for $f^{\prime \prime}(0)$, $\theta^{\prime}(0)$ and $\phi^{\prime}(0)$ and applying the fourth order classical "Rung-Kutta method" with step-size $\Delta \eta=0.01$. However, the above procedure is repeated until the converged results within a tolerance limit of $10^{-6}$ are obtained.

The accuracy of the results is examined with the published work Hayat et al. [15]. 
Table 1. Values of the fluid velocity, temperature, and nanoparticle concentration gradient at $\mathrm{Nb}=0.4, \mathrm{Nt}=0.3, \mathrm{Le}=2, \operatorname{Pr}=1, \mathrm{M}=0.4$, $\gamma_{3}=0.9$ and $\gamma_{1}=\gamma_{2}=1$

\begin{tabular}{lccc}
\hline & $-f^{\prime \prime}(0)$ & $-\theta^{\prime}(0)$ & $-\phi^{\prime}(0)$ \\
\hline Hayat et al. [15] & 1.459340 & 0.430912 & 0.318750 \\
\hline present & 1.459339 & 0.430912 & 0.318750 \\
\hline
\end{tabular}

\section{RESULTS}

The physical quantities that are interesting in this study are the skin friction coefficient, Nusselt and Sherwood numbers, which indicate physically to surface shear stress, rate of heat transfer, and rate of mass transfer respectively.

\subsection{Surface Shear Stress}

Surface shear stress can be defined as:

$$
\left\{\begin{array}{c}
\tau_{w}=\mu\left(\frac{\partial u}{\partial y}\right)_{y=\delta(x+b)^{\frac{1-n}{2}}} \\
=\mu U_{w} \sqrt{\frac{a}{v}\left(\frac{n+1}{2}\right)(x+b)^{n-1}} f^{\prime \prime}(0)
\end{array}\right\} .
$$

The skin friction coefficient is given by:

$$
C_{f}=\frac{2 \tau_{w}}{\rho U_{w}^{2}} \quad \text { i.e. } \quad 2 \sqrt{\left(\frac{n+1}{2}\right)} f^{\prime \prime}(0)=\sqrt{R_{e}} C_{f x} .
$$

\subsection{Surface Heat Flux}

Surface heat flux can be defined as:

$$
\left\{\begin{array}{c}
q_{w}=\left(q_{r}\right)_{w}-k\left(\frac{\partial T}{\partial y}\right)_{y=\delta(x+b)^{\frac{1-n}{2}}} \\
=-k\left(T_{w}-T_{\infty}\right) \sqrt{\left(\frac{n+1}{2}\right) \frac{a}{v}}(x+b)^{\frac{n-1}{2}} \theta^{\prime}(0)
\end{array}\right\} .
$$

Since the Nusselt number is given by:

$$
\begin{aligned}
& N u=\frac{(x+b) q_{w}}{k\left(T_{w}-T_{\infty}\right)} \text { i.e. } \\
& N u=-\left[\sqrt{\frac{n+1}{2}} \sqrt{R_{e}}+\frac{4 R d \theta_{w}^{3}}{3}\right] \theta^{\prime}(0) .
\end{aligned}
$$

\subsection{Surface Mass Flux}

Surface mass flux can be defined as:

$$
\left\{\begin{array}{c}
q_{m}=-D_{B}\left(\frac{\partial C}{\partial y}\right)_{y=\delta(x+b)^{\frac{1-n}{2}}} \\
=-D_{B}\left(C_{w}-C_{\infty}\right) \sqrt{\left(\frac{n+1}{2}\right) \frac{a}{v}}(x+b)^{\frac{n-1}{2}} \varphi^{\prime}(0)
\end{array}\right\} .
$$

Since the Sherwood number is given by:

$$
S h=\frac{(x+b) q_{m}}{D_{B}\left(C_{w}-C_{\infty}\right)} \text { i.e. } \frac{S h}{\sqrt{R_{e}}}=-\sqrt{\frac{n+1}{2}} \varphi^{\prime}(0) .
$$

\section{DISCUSSION}

The velocity, temperature and concentration profiles with the variation of all embedded parameters are shown in Figs. 2 to 18.

Figs. 2 to 4 present the influence of the thickness parameter $\alpha$. It is observed that increasing of $\alpha$ leads to decreasing the velocity, temperature and concentration in the case of $n<1$ and the opposite is true for $n>1$ and no effect of this parameter on the boundary layer in the case of flat surface $n=0$. Moreover, one can observe that the surface temperature is higher in the case of $n>1$ than that in the case of $n<1$, and the influence of the thickness parameter on the temperature changes by changing the value of $\mathrm{n}$ such that in the case of $n>1$ the temperature Increases by the increase of the value of the thickness parameter and the opposite is true for $n<1$.

In addition, the nanoparticles concentration increases by increasing the thickness parameter in the case of $n>1$ and decreases in the case of $n<1$. Figs. 5 to 7 show the effect of magnetic field parameter on the boundary layer velocity, temperature, and concentration respectively.

It is clear that the increase of the magnetic parameter decreases the velocity and the opposite is true for the temperature and nanoparticles concentration.

The effect of non-linear thermal radiation appears in the dimensionless system through the radiation parameter $\mathrm{Rd}$ and temperature ratio parameter $\theta_{w}$. The effects of the radiation parameter on the boundary layer temperature and concentration are exhibited in Figs. 8 and 9. It is clear that the effect of this parameter near the surface differs from its effect far from the surface such that the increasing of the radiation parameter near the surface decreases the temperature near the surface to a certain point at which the effect is reversed. In contrast, the increase of such parameter increases the temperature of the boundary layer.

In contrast, the effects of the temperature ratio on the boundary layer temperature and concentration are 


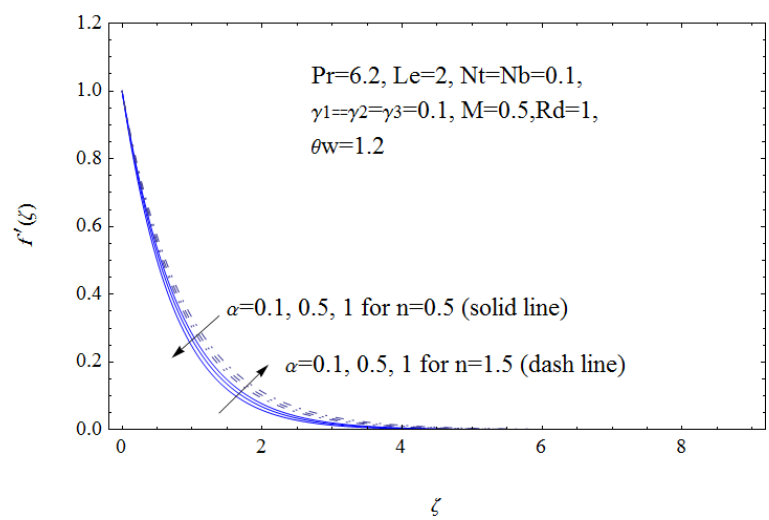

Fig. 2. Influence of thickness parameter on the velocity

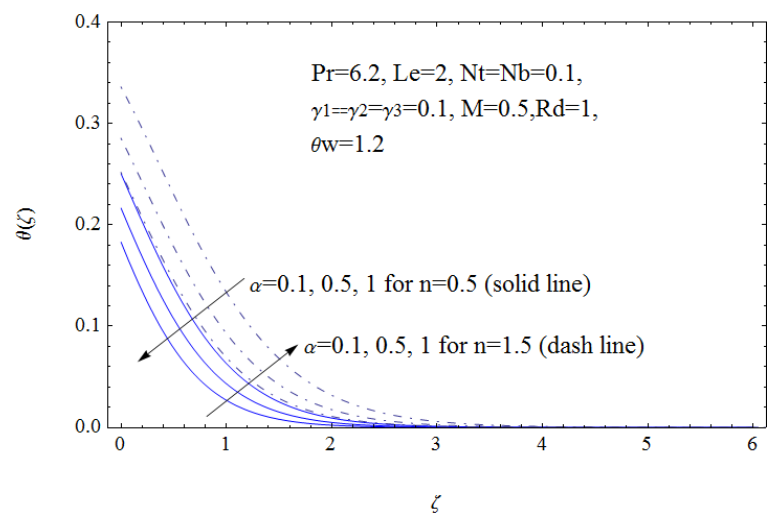

Fig. 3. Influence of thickness parameter on the temperature

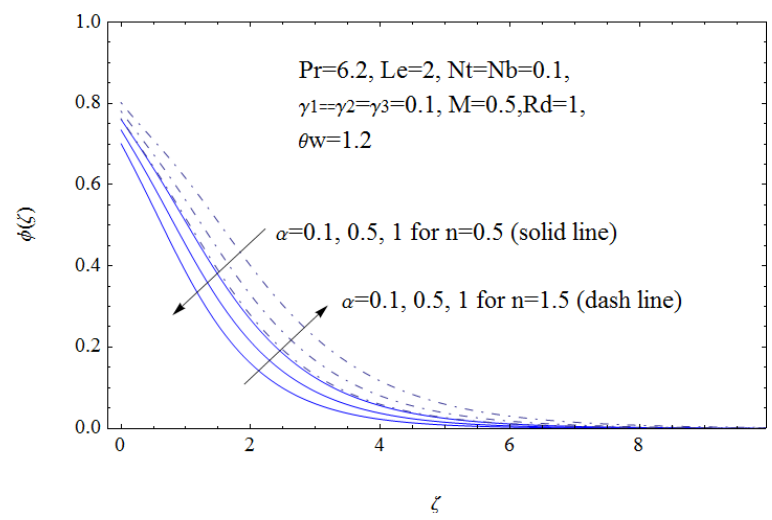

Fig. 4. Influence of thickness parameter on the concentration

shown in Figs. 10 and 11. The figures show that the increase of the temperature ratio decreases both the temperature and the concentration of the nanoparticles near the surface.

The effects of Biot numbers on the temperature and nanoparticles concentration are shown in Figs. 12 to 14. It is clear that the temperature and nanoparticle concentration both increase by the increase in thermal Biot number and concentration Biot number.

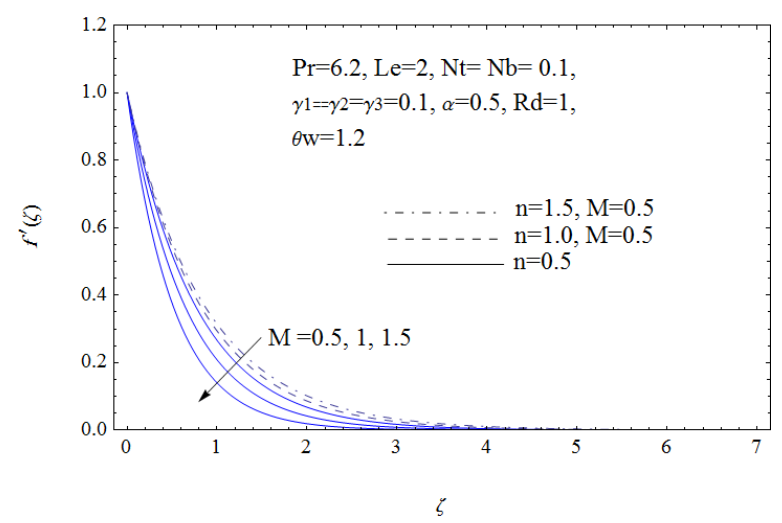

Fig. 5. Influence of magnetic parameter on the velocity

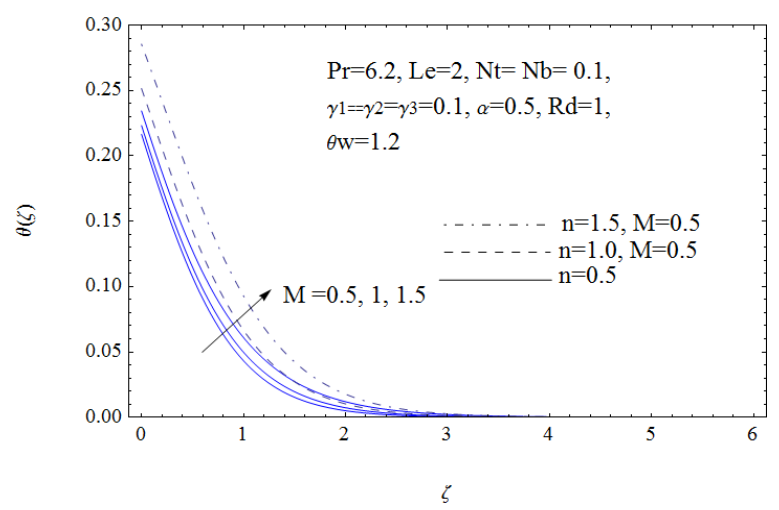

Fig. 6. Influence of magnetic parameter on the temperature

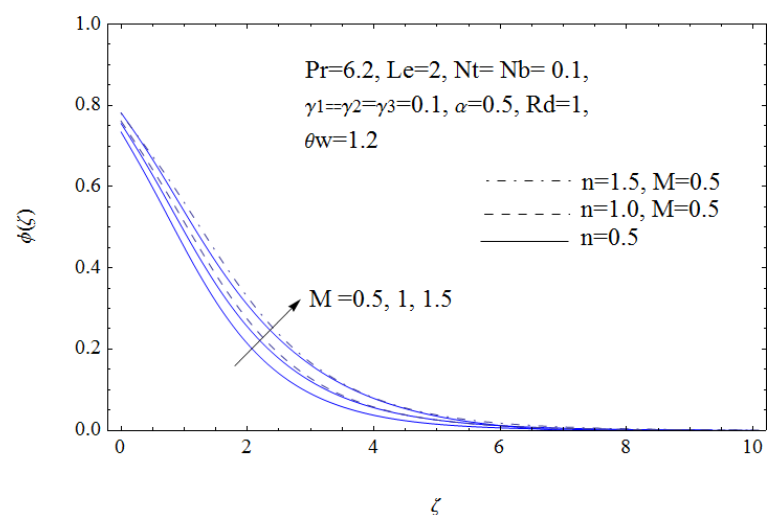

Fig. 7. Influence of magnetic parameter on the concentration

The effect of random motion of the nanoparticles within the fluid appears in this study through the Brownian motion parameter Nb. Referring to Figs. 15 and 16 , one can observe that increasing $\mathrm{Nb}$ leads to an increase in the temperature and a decrease of the nanoparticles concentration. Moreover, one can observe that the impact of the random moving of particles on the concentration decreases by increasing the value of Brownian motion parameter for all values of the shape parameter $n$. 


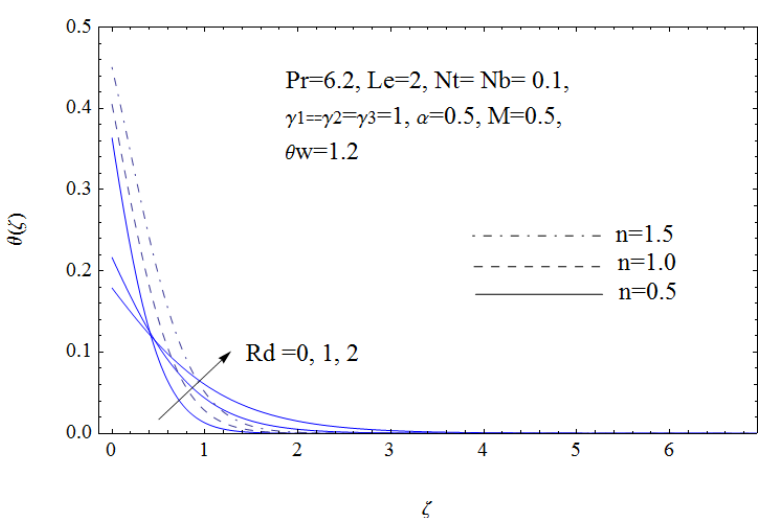

Fig. 8. Influence of radiation parameter on the temperature

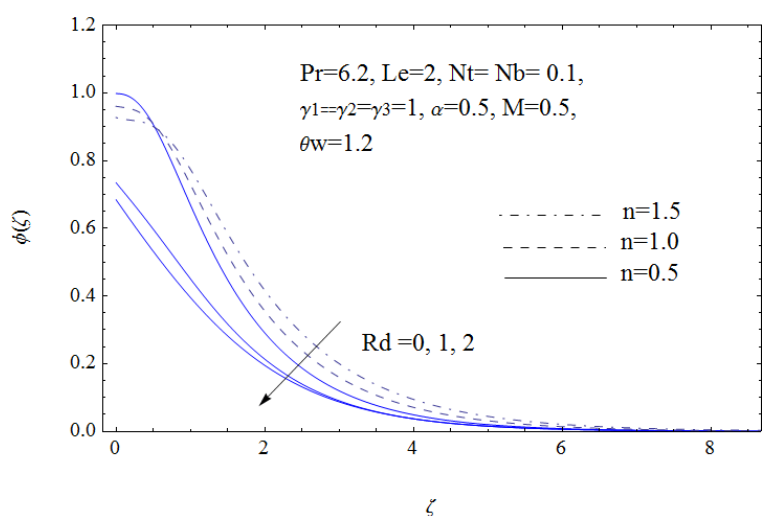

Fig. 9. Influence of radiation parameter on the concentration

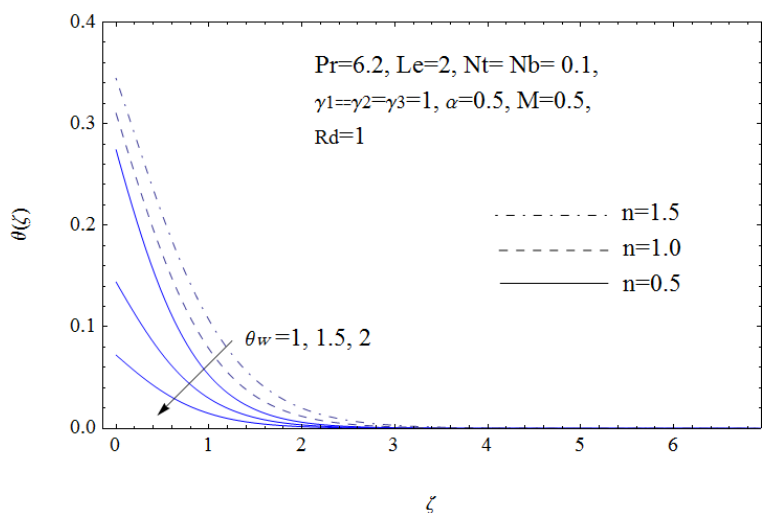

Fig. 10. Influence of temperature ratio parameter on the temperature

The Thermophoresis parameter $\mathrm{Nt}$ is a dimensionless parameter that describes the response of the suspended particles to the force of the temperature gradient. Figs. 17 amd 18 show that the increase of this parameter leads to increasing the boundary layer temperature and nanoparticles concentration. Moreover, Fig. 18 shows that the effect of this phenomenon on the concentration is very clear in the case of $n>1$. In addition, one can observe that

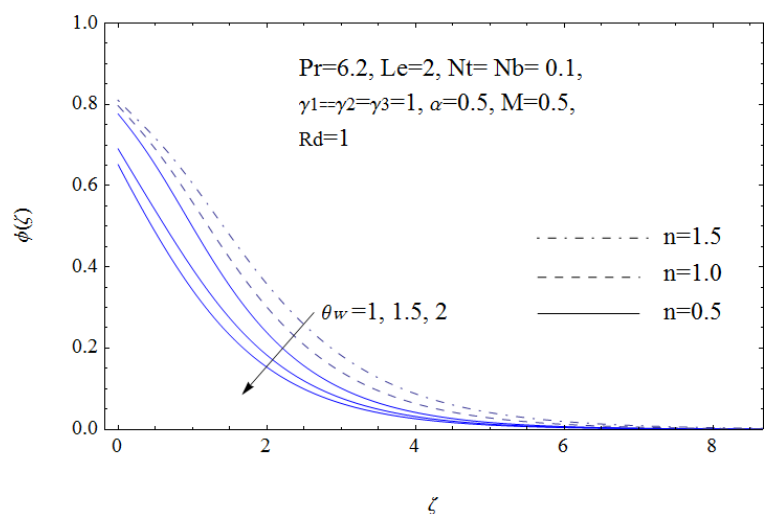

Fig. 11. Influence of temperature ratio parameter on the concentration

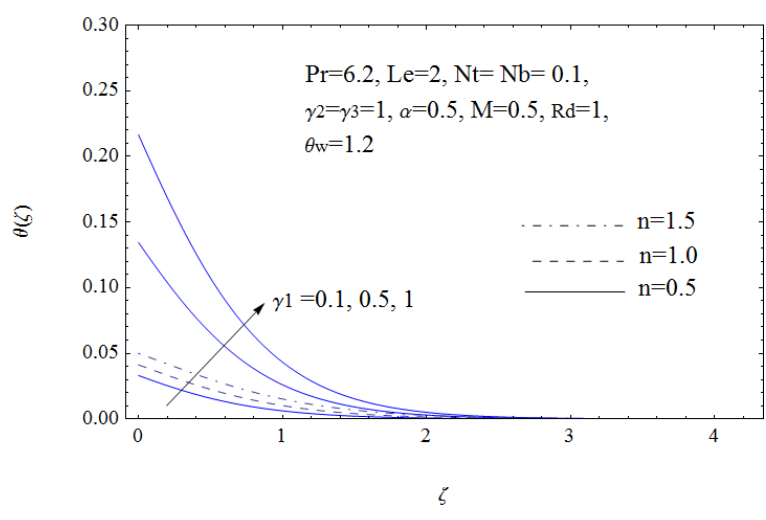

Fig. 12. Influence of thermal ratio parameter on the temperature

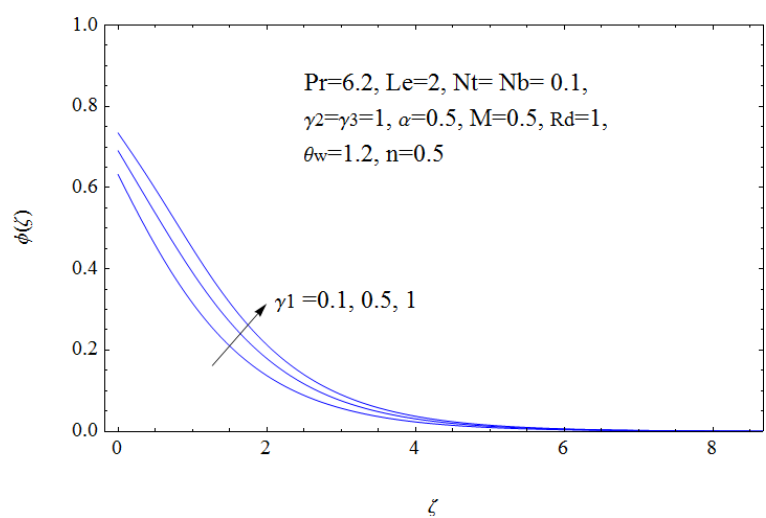

Fig. 13. Influence of thermal ratio parameter on the concentration

increasing the thermophoresis parameter leads to forming a concentrated zone of the nanoparticles near the surface.

The main objective of this work is to study the effects of convective condition with the thickness variation and the nonlinear thermal radiation on the boundary layer behaviour.

Table 2 presents the values of the skin friction, Nusselt number and the Sherwood number for linear 


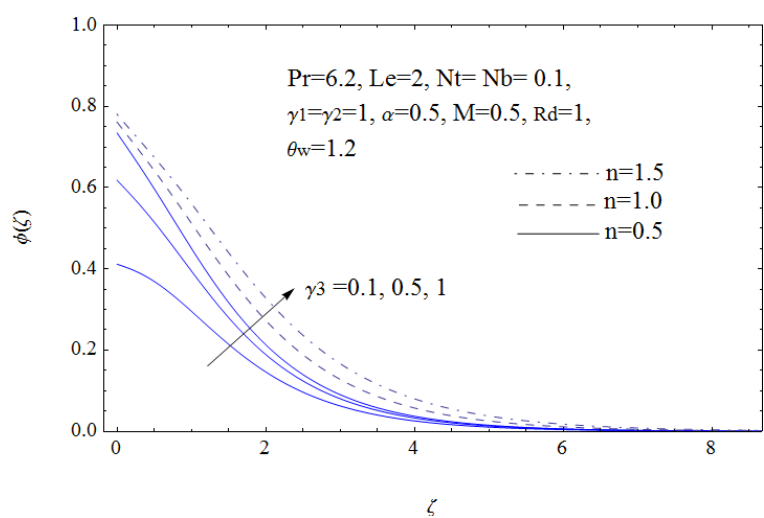

Fig. 14. Influence of concentration Biot number on the concentration

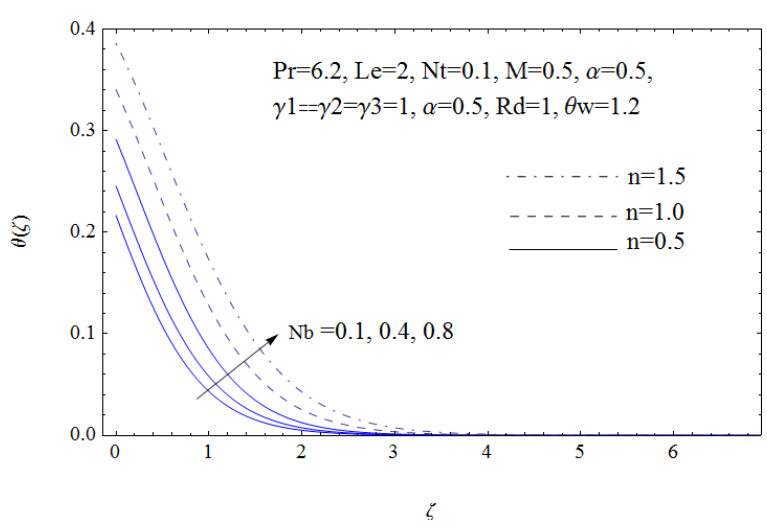

Fig. 15. Influence of Brownian motion parameter on the temperature

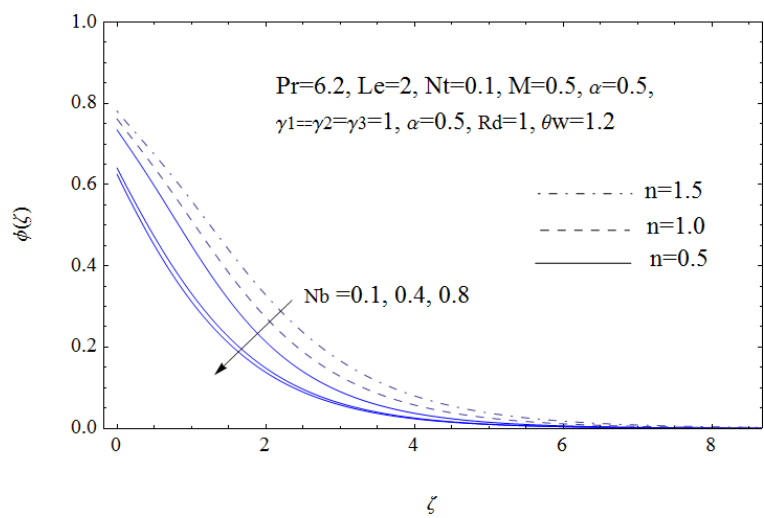

Fig. 16. Influence of Brownian motion parameter on the concentration

and non-linear thermal radiation at three cases of shape parameter $n$. from the first look, one can observe that the skin friction and Sherwood number values increase with the increase of the shape parameter $n$. Such increasing of $n$ decreases the values of the Nusselt number. Moreover, one can observe that the presence of thermal radiation increases the Nusselt

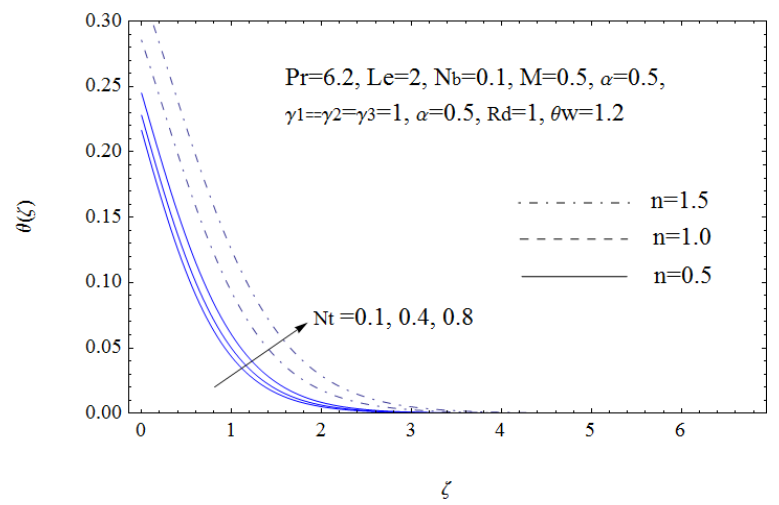

Fig. 17. Influence of thermophoresis parameter on the concentration

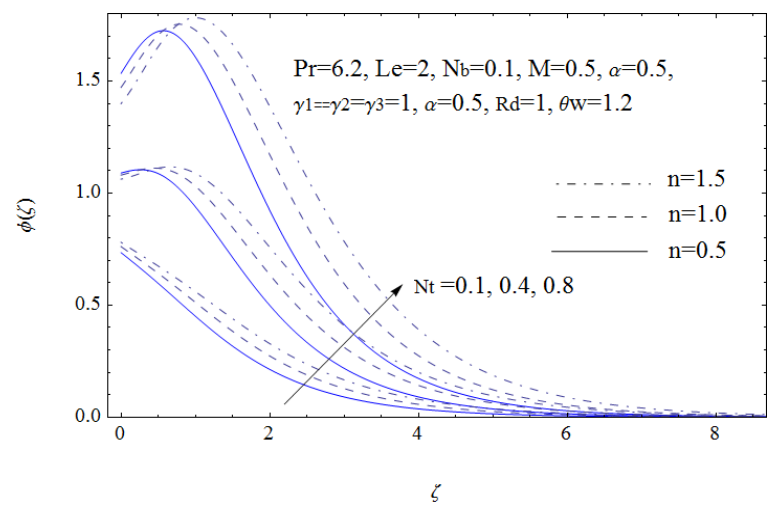

Fig. 18. Influence of thermophoresis parameter on the concentration

and Sherwood numbers. Finally, the values obtained in Table 2 indicate that the nonlinear modelling of the thermal radiation gives high values for Nusselt and Sherwood numbers. It is worth mentioning that the increasing of the skin friction and Nusselt number values to the increase of surface shear stress and the rate of heat transfer from the surface.

The effects of hydromagnetic flow on the skin friction, Nusselt number and Sherwood number are shown in Table 3. The observed results show that using hydromagnetic flow as a cooling medium increases skin friction, and decrease Nusselt number and Sherwood number. Consequently, the surface shear stress is increased, and the rate of heat transfer and rate of mass transfer is decreased by increasing the magnetic parameter $M$.

Table 4 shows the influence of thermal Biot number on the Nusselt and Sherwood Numbers. It is clear that the increase of the heat convective coefficient increases the heat flux and decreases the mass flux relative to the increasing and decreasing of the Nusselt and Sherwood Numbers, respectively. In contrast, the effect of concentration Biot number on 
Table 2. Values of skin friction, Nusselt number and Sherwood number for linear and non-linear thermal radiation at $L e=2, P r=6.2$, $N t=N b=0.1, M=0.5, \alpha=0.5$, and $\gamma_{1}=\gamma_{2}=\gamma_{3}=0.1$

\begin{tabular}{|c|c|c|c|c|c|c|c|c|}
\hline$\theta_{w}$ & $\mathrm{Rd}$ & $n$ & $-f^{\prime \prime}(0)$ & $-\theta^{\prime}(0)$ & $-\phi^{\prime}(0)$ & $C f x$ & $\mathrm{Nu}$ & $S h$ \\
\hline \multirow{3}{*}{1} & \multirow{3}{*}{1} & 0.5 & 1.2807 & 0.0439 & 0.0814 & 2.2183 & 0.0966 & 0.0705 \\
\hline & & 1.0 & 1.2247 & 0.0411 & 0.0793 & 2.4495 & 0.0960 & 0.0793 \\
\hline & & 1.5 & 1.1827 & 0.0383 & 0.0774 & 2.6446 & 0.0953 & 0.0866 \\
\hline \multirow{6}{*}{1.2} & \multirow{3}{*}{0} & 0.5 & 1.2807 & 0.1099 & 0.0733 & 2.2183 & 0.0951 & 0.0635 \\
\hline & & 1.0 & 1.2247 & 0.0943 & 0.0722 & 2.4495 & 0.0943 & 0.0722 \\
\hline & & 1.5 & 1.1827 & 0.0834 & 0.0713 & 2.6446 & 0.0933 & 0.0797 \\
\hline & \multirow{3}{*}{1} & 0.5 & 1.2807 & 0.0308 & 0.0829 & 2.2183 & 0.0976 & 0.0718 \\
\hline & & 1.0 & 1.2247 & 0.0294 & 0.0807 & 2.4495 & 0.0971 & 0.0807 \\
\hline & & 1.5 & 1.1827 & 0.0282 & 0.0788 & 2.6446 & 0.0966 & 0.0881 \\
\hline
\end{tabular}

Table 3. Values of skin friction, Nusselt number and Sherwood number for MHD flow at $\alpha=0.5, \operatorname{Le}=2, \operatorname{Pr}=6.2, N t=N b=0.1, \theta_{w}=1.2, R d=1$ and $\gamma_{1}=\gamma_{2}=\gamma_{3}=1$

\begin{tabular}{cccccccc}
\hline M & $n$ & $-f^{\prime \prime}(0)$ & $-\theta^{\prime}(0)$ & $-\phi^{\prime}(0)$ & $C f x$ & $N u$ & $S h$ \\
\hline \multirow{3}{*}{0.5} & 0.5 & -1.2807 & -0.2472 & -0.2653 & -0.0031 & 151.93 & 162.45 \\
\cline { 2 - 8 } & 1.00 & -1.2247 & -0.2266 & -0.2384 & -0.0035 & 160.73 & 168.56 \\
\cline { 2 - 8 } & 1.50 & -1.1827 & -0.2089 & -0.2192 & -0.0037 & 165.60 & 173.26 \\
\cline { 2 - 8 } & 0.5 & -1.5297 & -0.2450 & -0.2443 & -0.0037 & 150.45 & 149.61 \\
\cline { 2 - 8 } & 1.00 & -1.4142 & -0.2241 & -0.2177 & -0.0040 & 158.95 & 153.96 \\
\hline \multirow{2}{*}{2} & 1.50 & -1.3351 & -0.2060 & -0.1991 & -0.0042 & 163.32 & 157.43 \\
\hline & 0.5 & -1.9310 & -0.2415 & -0.2181 & -0.0047 & 148.45 & 133.57 \\
\hline & 1.00 & -1.7321 & -0.2196 & -0.1854 & -0.0049 & 155.77 & 131.10 \\
\hline & 1.50 & -1.5981 & -0.2006 & -0.1675 & -0.0051 & 159.02 & 132.41 \\
\hline
\end{tabular}

Table 4. Values of Nusselt number and Sherwood number for different values of thermal Biot number $\alpha=0.5, L e=2, \operatorname{Pr}=6.2$, $R d=1, \theta_{w}=1.2, M=0.5, N t=N b=0.1$ and $\gamma_{1}=\gamma_{3}=1$

\begin{tabular}{cccccc}
\hline$\gamma_{2}$ & $n$ & $-\theta^{\prime}(0)$ & $-\phi^{\prime}(0)$ & $N u$ & $S h$ \\
\hline \multirow{3}{*}{0.1} & 0.50 & 0.08478 & 0.34525 & 0.26876 & 0.29900 \\
\cline { 2 - 6 } & 1.00 & 0.07490 & 0.31222 & 0.24747 & 0.31222 \\
\cline { 2 - 6 } & 1.50 & 0.06771 & 0.28563 & 0.23170 & 0.31935 \\
\hline \multirow{3}{*}{0.5} & 0.50 & 0.20411 & 0.28636 & 0.64704 & 0.24799 \\
\cline { 2 - 6 } & 1.00 & 0.18533 & 0.25829 & 0.61235 & 0.25829 \\
\cline { 2 - 6 } & 1.50 & 0.17000 & 0.23725 & 0.58175 & 0.26525 \\
\hline \multirow{3}{*}{1} & 0.50 & 0.24716 & 0.26528 & 0.78351 & 0.22974 \\
\cline { 2 - 6 } & 1.00 & 0.22657 & 0.23839 & 0.74859 & 0.23839 \\
\cline { 2 - 6 } & 1.50 & 0.20886 & 0.21915 & 0.71473 & 0.24502 \\
\hline
\end{tabular}

the rate of heat and mass transfer is shown in Table 5. The effect of this number on the Nusselt number is low and limited, but it has a direct effect on the Sherwood number and the mass flux such that increasing the concentration Biot number increases the mass flux.

\section{CONCLUSIONS}

This study presents a mathematical model of a continuous moving non-flat surface over a hot
Table 5. Values of Nusselt number and Sherwood number for different values of concentration Biot number $L e=2, \operatorname{Pr}=6.2$, $R d=1, \theta_{w}=1.2, M=0.5, \alpha=0.5, N t=N b=0.1$ and $\gamma_{1}=\gamma_{2}=1$

\begin{tabular}{cccccc}
\hline$\gamma_{3}$ & $n$ & $-\theta^{\prime}(0)$ & $-\phi^{\prime}(0)$ & $N u$ & $S h$ \\
\hline \multirow{3}{*}{0.1} & 0.50 & 0.24863 & 0.05885 & 0.78818 & 0.05096 \\
\cline { 2 - 6 } & 1.00 & 0.22822 & 0.05719 & 0.75403 & 0.05719 \\
\cline { 2 - 6 } & 1.50 & 0.21066 & 0.05630 & 0.72087 & 0.06295 \\
\hline \multirow{3}{*}{0.5} & 0.50 & 0.24770 & 0.19088 & 0.78521 & 0.16530 \\
\cline { 2 - 6 } & 1.00 & 0.22714 & 0.17631 & 0.75047 & 0.17631 \\
\cline { 2 - 6 } & 1.50 & 0.20945 & 0.16585 & 0.71676 & 0.18543 \\
\hline \multirow{3}{*}{1} & 0.50 & 0.24716 & 0.26528 & 0.78351 & 0.22974 \\
\cline { 2 - 6 } & 1.00 & 0.22657 & 0.23839 & 0.74859 & 0.23839 \\
\cline { 2 - 6 } & 1.50 & 0.20886 & 0.21915 & 0.71473 & 0.24502 \\
\hline
\end{tabular}

convective fluid subjected to nonlinear thermal radiation and magnetic field. Above the surface, there is a Nanofluid boundary layer with Brownian motion and thermophoresis effects. The heat and mass transfer characteristics of the boundary layer are the main concern of this study, and the following results are obtained:

- The values of the Nusselt and Sherwood numbers for non-linear thermal radiation model are high comparing with a linear model. 
- Surface shear stress for the convex outer shape surface $(n<1)$ is higher than that in the case of concave outer shape surface $(n>1)$.

- The presence of convective conditions decreases surface heat flux and mass flux.

- The random motions of the nanoparticles and the thermophoresis force have direct and high influences on the concentration boundary layer, especially for the non-flat surface.

\section{NOMENCLATURES}

$u \quad$ velocity in the $x$ direction $[\mathrm{m} / \mathrm{s}]$,

$v$ velocity in the $y$ direction $[\mathrm{m} / \mathrm{s}]$,

$v \quad$ kinematic viscosity $\left[\mathrm{m}^{2} / \mathrm{s}\right]$,

$a, b, \delta$ constants [-],

$T$ temperature $\left[{ }^{\circ} \mathrm{C}\right]$,

$C$ concentration $\left[\mathrm{mol} / \mathrm{m}^{3}\right]$,

$C_{p}$ specific heat capacity $[\mathrm{J} /(\mathrm{kg} \cdot \mathrm{K})]$,

$k$ thermal conductivity $[\mathrm{W} /(\mathrm{m} \cdot \mathrm{K})]$,

$h$ convective heat transfer coefficient [-],

$k_{m}$ surface mass transfer coefficient [-],

$D_{B}$ Brownian diffusion $\left[\mathrm{m}^{2} / \mathrm{s}\right]$,

$D_{T}$ thermophoresis diffusion $\left[\mathrm{m}^{2} / \mathrm{s}\right]$,

$q_{r}$ heat flux $\left[\mathrm{W} / \mathrm{m}^{2}\right]$,

$\rho$ density of the base fluid $\left[\mathrm{kg} / \mathrm{m}^{3}\right]$,

$\sigma$ electrical conductivity [s/m],

$B(x)$ strength of the magnetic field $\left[\mathrm{kg} /\left(\mathrm{s}^{2} \cdot \mathrm{m}\right)\right]$,

$\alpha^{\times}$thermal diffusion $\left[\mathrm{m}^{2} / \mathrm{s}\right]$,

$\alpha^{*} \quad$ Rosseland mean absorption coefficient [-],

$\eta, \zeta$ similarity variables [-],

$\theta(\eta)$ dimensionless temperature [-],

$\phi(\eta)$ dimensionless concentration [-],

$\sigma^{*}$ Boltzmann constant, $\left[\mathrm{m}^{2} \cdot \mathrm{kg} /\left(\mathrm{s}^{2} \cdot \mathrm{K}\right)\right]$

$\alpha$ thickness parameter, $\alpha=\delta \sqrt{\frac{1+n}{2} \frac{a}{v}}[-]$,

$\theta_{w}$ temperature ratio, $\theta_{w}=T_{w} / T_{\infty}[-]$,

$\operatorname{Pr}$ Prandtl number, $\operatorname{Pr}=v / \alpha[-]$

Le Lewis number, $\mathrm{Le}=v / D_{B}[-]$,

$\mathrm{M}$ magnetic field parameter, $\mathrm{M}=\frac{\beta_{0}^{2} \sigma}{a \rho}[-]$,

$\mathrm{Rd}$ radiation parameter, $\mathrm{Rd}=\frac{4 \sigma^{*} T_{\infty}^{3} \rho}{k \alpha^{*}}[-]$,

$\mathrm{Nb}$ Brownian parameter, $N b=\frac{\tau D_{B}}{v}\left(C_{w}-C_{\infty}\right)[-]$,

$\mathrm{Nt}$ thermophoresis parameter, $N t=\frac{\tau D_{t}}{v T_{\infty}}\left(T_{w}-T_{\infty}\right)[-]$,

$\gamma_{1}$ thermal ratio, $\gamma_{1}=h / k,[-]$

$\gamma_{2}$ thermal Biot number, $\gamma_{2}=\frac{h}{k} \sqrt{\frac{v}{a(x+b)^{n-1}}}[-]$,

$\gamma_{3}$ concentration Biot number, $\gamma_{3}=\frac{k_{m}}{D_{m}} \sqrt{\frac{v}{(\alpha+x+b)^{n-1}}}[-]$,

$\tau \quad$ specific heat capacity ratio, $\tau=\frac{(\rho C p)_{p}}{(\rho C p)_{f}}[-]$

\section{REFERENCES}

[1] Choi, S.U.S., J.A. Estman (1995). Enhancing thermal conductivity of fluids with nanoparticles. Proceedings of the ASME International Mechanical Engineering Congress \& Exposition, vol. 231, p. 99-105.

[2] Hamad, M.A.A. (2011). Analytical solution of natural convection flow of a Nanofluid over a linearly stretching sheet in the presence of magnetic field. International Communications in Heat and Mass Transfer, vol. 38, no. 4, p. 487-492, D0I:10.1016/j.icheatmasstransfer.2010.12.042.

[3] Yacob, N.A., Ishak, A., Pop, I., Vajravelu, K. (2011). Boundary layer flow past a stretching/ shrinking surface beneath an external uniform shear flow with a convective surface boundary condition in a Nanofluid. Nanoscale Research Letters, vol. 6, 1-7, Dol:10.1186/1556-276X-6-314.

[4] Alsaedi, A., Awai, s M., Hayat, T. (2012). Effects of heat generation/absorption on stagnation point flow of Nanofluid over a surface with convective boundary conditions. Communications in Nonlinear Science and Numerical Simulation, vol. 17, no. 11, p. 4210-4223, D0l:10.1016/j. cnsns.2012.03.008.

[5] Elbashbeshy E.M.A., Emam T.G., and Abdel-wahed M.S. (2014). An exact solution of boundary layer flow over a moving surface embedded into a nanofluid in the presence of magnetic field and suction/injection. Heat and Mass Transfer, vol. 50, no. 1, p. 57-64, D0l:10.1007/s00231-013-1224-x.

[6] Abu Bakar N.A., Zaimi W.M.K.A.W., Abdul Hamid R., Bidin, B., Ishak, A. (2012). Boundary layer flow over a stretching sheet with a convective boundary condition and slip effect. World Applied Sciences Journal, vol. 17, p. 49-53.

[7] Öztürk, A., Kahveci, K. (2016). Slip flow of nanofluids between parallel plates heated with a constant heat flux. Strojniški vestnik - Journal of Mechanical Engineering, vol. 62, no. 9, p. 511-520, D0I:10.5545/sv-jme.2016.3188.

[8] Noghrehabadi A., Pourrajab R., Ghalambaz M. (2013).Flow and heat transfer of nanofluids over stretching sheet taking into account partial slip and thermal convective boundary conditions. Heat and Mass Transfer, vol. 49, no. 9, p. 13571366, D0I:10.1007/s00231-013-1179-y.

[9] Rahman, M.M., Eltayeb, I.A. (2013). Radiative heat transfer in a hydromagnetic nanofluid past a non-linear stretching surface with convective boundary condition. Meccanica, vol. 48, no. 3, p. 601-615, D0I:10.1007/s11012-012-9618-2.

[10] Ramesh, G.K., Gireesha B.J. (2014). Influence of heat source/sink on a Maxwell fluid over a stretching surface with convective boundary condition in the presence of nanoparticles. Ain Shams Engineering Journal, vol. 5, no. 3, p. 991-998, D0I:10.1016/j.asej.2014.04.003.

[11] Nadeem, S., Haq, R.U. (2014). Effect of thermal radiation for megnetohydrodynamic boundary layer flow of a nanofluid past a stretching sheet with convective boundary conditions. Journal of Computational and Theoretical Nanoscience, vol. 11, n. 1-9, p. 32-40, D0l:10.1166/jctn.2014.3313.

[12] Chamkha, A.J., Rashad, A.M., RamReddy, C., Murthy, P.V.S.N. (2014). Viscous dissipation and magnetic field effects in a non-Darcy porous medium saturated with a nanofluid under convective boundary condition. Special Topics \& Reviews 
in Porous Media, vol. 5, no. 1, p. 27-39, Dol:10.1615/ SpecialTopicsRevPorousMedia.v5.i1.30.

[13] RamReddy Ch., Murthy P.V.S.N., Chamkha, A.J., Rashad, A.M. (2013). Soret effect on mixed convection flow in a Nanofluid under convective boundary condition. International Journal of Heat and Mass Transfer, vol. 64, p. 384-392, D0l:10.1016/j. ijheatmasstransfer.2013.04.032.

[14] Ibrahim, W., Shankar, B. (2013). MHD boundary layer flow and heat transfer of a nanofluid past a permeable stretching sheet with velocity, thermal and solutal slip boundary conditions. Computers \& Fluids, vol. 75, p. 1-10, D0l:10.1016/j. compfluid.2013.01.014.

[15] Hayat, T., Imtiaz, M, Alsaedi, A. (2014). MHD flow of nanofluid over permeable stretching sheet with convective boundary conditions, Thermal Science (On-line first), Dol:10.2298/ TSCI140819139H.

[16] Fang, T., Zhang, J., Zhong ,Y. (2012). Boundary layer flow over a stretching sheet with variable thickness. Applied
Mathematics and Computation, vol. 218, no. 13, p. 7241 7252, D0I:10.1016/j.amc.2011.12.094.

[17] Elbashbeshy, E.M.A, Emam, T.G., Abdel-wahed, M.S. (2013). Flow and heat transfer over a moving surface with non-linear velocity and variable thickness in a nanofluid in the presence of thermal radiation. Canadian Journal of Physics, vol. 91, no. 2, p. 124-130, Dol:10.1139/cjp-2013-0168.

[18] Abdel-wahed, M.S., Elbashbeshy, E.M.A., Emam, T.G. (2015). Flow and heat transfer over a moving surface with non-linear velocity and variable thickness in a Nanofluid in the presence of Brownian motion. Applied Mathematics and Computation, vol. 254, p. 49-62, D0l:10.1016/J.amc.2014.12.087.

[19] Pantokratoras, A., Fang, T. (2013). Sakiadis flow with nonlinear Rosseland thermal radiation. Physica Scripta, vol. 87, no. 1, DOI:10.1088/0031-8949/87/01/015703.

[20] Abdel-wahed, M.S., Akl, M. (2016). Effect of hall current on MHD flow of a nanofluid with variable properties due to a rotating disk with viscous dissipation and nonlinear thermal radiation. AIP Advances, vol. 6, no. 9, Dol:10.1063/1.4962961. 